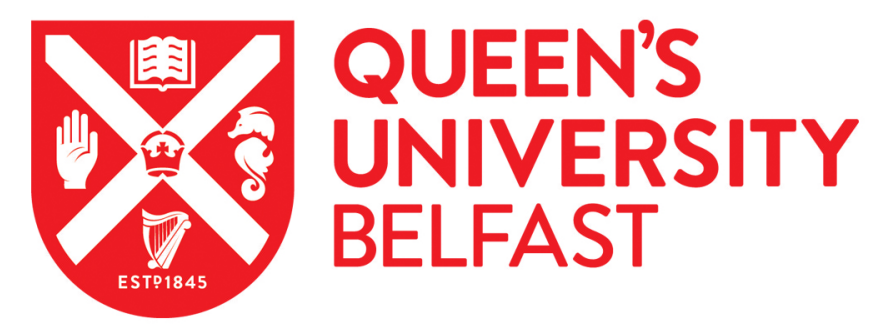

\title{
Ruggedized Surface-mount Omni-directional Antenna for Supersonic Aerial Platforms
}

Nawaz, H., Liang, X., SADIQ, MUHAMMAD. SHAHZAD., \& Abbasi, M. A. B. (2020). Ruggedized Surface-mount Omni-directional Antenna for Supersonic Aerial Platforms. IEEE Antennas and Wireless Propagation Letters, 19(8). https://doi.org/10.1109/lawp.2020.3004702

Published in:

IEEE Antennas and Wireless Propagation Letters

Document Version:

Peer reviewed version

Queen's University Belfast - Research Portal:

Link to publication record in Queen's University Belfast Research Portal

Publisher rights

(c) 2020 IEEE.

This work is made available online in accordance with the publisher's policies. Please refer to any applicable terms of use of the publisher.

\section{General rights}

Copyright for the publications made accessible via the Queen's University Belfast Research Portal is retained by the author(s) and / or other copyright owners and it is a condition of accessing these publications that users recognise and abide by the legal requirements associated with these rights.

Take down policy

The Research Portal is Queen's institutional repository that provides access to Queen's research output. Every effort has been made to ensure that content in the Research Portal does not infringe any person's rights, or applicable UK laws. If you discover content in the Research Portal that you believe breaches copyright or violates any law, please contact openaccess@qub.ac.uk. 


\title{
Ruggedized Surface-mount Omni-directional Antenna for Supersonic Aerial Platforms
}

\author{
Hamza Nawaz, Xianling Liang, Senior Member, IEEE, M. Shahzad Sadiq, Graduate Student Member, IEEE, \\ M. Ali Babar Abbasi, Member, IEEE
}

\begin{abstract}
A rugged metal protected antenna that produces an omnidirectional radiation pattern is proposed in this letter. The omnidirectionality is achieved by using a cavity enclosed PCB (Printed Circuit Board) with $\lambda / 4$ transformers and ground shortening pins combination. The slotted cavity filled with ablative material is designed to maintain the radiation characteristics of the enclosed $\mathrm{PCB}$ and provide strength for the antenna arrangement, which can be effectively used on high-speed aerial platforms. The simulated and measured results demonstrate that the proposed antenna possesses a stable omnidirectional radiation pattern, its horizontal gain is higher than $\mathbf{- 1 . 5} \mathbf{~ d B}$, the azimuthal gain ripple is within \pm $0.7 \mathrm{~dB}$, and the antenna efficiency exceeds $85 \%$, over the entire operational frequency band. In addition, the conformal, tapered, non-protruding, lowprofile and DC-grounded design makes winged antennas superior candidate for supersonic (Mach> 1) airborne applications.
\end{abstract}

Index Terms - Airborne antenna, conformal antenna, aerodynamically stable, cavity enclosed radiator, high-speed platforms

\section{INTRODUCTION}

On high-speed aerial platforms, blade and stub antennas are generally deployed, because of their omnidirectional radiation characteristics and uniform horizontal gain with vertical polarization $[1,2]$. Nevertheless, such antennas protrude from aerial platforms, which enhances the radar-cross-section (RCS). Reduced RCS is critical and vital for stealth and defense applications [3, 4]. Moreover, the protruding structure increases air resistance, increases cabin noise, and is more susceptible to damage and corrosion, due to high-speed mobility or high aero-heating environment [5-7].

Surface-mounted or flush-mounted conformal antennas are the focus of high-speed platforms for reliable aerodynamic performance. These configurations can be designed using the concept of shunt fed antennas, available in classical literature $[8,9]$, whose variants lead to recent innovations, like the one in [10]. Airborne communication systems require omnidirectional antennas with good horizontal gain and low azimuth gain ripple to achieve stable discontinuous coverage at all yaw angles $[11,12]$. An omnidirectional conformal on-glass antenna with coupled-feed was presented in [13], targeting durability and to minimize weight and wind resistance. But its azimuth gain is very low, below $-10 \mathrm{~dB}$ at several angles. In [14], a conformal antenna using an L-shaped monopole configuration was exhibited, but with a quasi-omnidirectional horizontal pattern, having gain ripple of $6 \mathrm{~dB}$ in azimuth plane. In [15], an inverted Lshaped aircraft antenna using ground edge current was proposed.

Manuscript received May, 2020. This work was supported in part by the National Natural Science Foundation of China under Grant 61671416 and 61801447. (Corresponding author: Xianling Liang)

Hamza Nawaz and Xianling Liang, are with Department of Electronics Engineering, School of Electrical, Information and Electronics Engineering, Shanghai Jiao Tong University, Shanghai 200240, China. Email: liangxl@sjtu.edu.cn,hamza_nawaz@hotmail.com.

M. Shahzad Sadiq is with School of Electronics and Information Engineering, Beihang University, Beijing, 100191, China.

M. Ali Babar Abbasi is with Institute of Electronics, Communication and Information Technology, Queen's University Belfast, Belfast, BT7 1NN, U.K
Nevertheless, with the high azimuth gain ripple of $10 \mathrm{~dB}$. A conformal sabre-like structure with an omnidirectional radiation pattern, having the yaw plane gain change of $3.45 \mathrm{~dB}$ was proposed in [16] for airborne applications.

On the other hand, with the development of technology, kinetic kill weapons and ultra-high-speed vehicles have become technically and economically feasible [17]. Such platforms have to face extreme aerodynamic circumstances, which will put more pressure on the PCB materials/printed antennas than they can handle. Therefore, in addition to low-profile and surface-mount antennas, closed antennas based on metal alloys or metal cavities must also be used to provide shielding for vulnerable components to withstand harsh conditions and to have better heat and damage resistance [18].

In this letter, for targeting the beam-pattern and aerodynamic requirements of high-speed aviation platform applications, a metal cavity embedded, DC grounded, surface-mounted antenna is proposed, which has an omnidirectional radiation pattern with good uniform horizontal gain and low azimuth gain ripple. Section II describes the structure and principle of the proposed antenna arrangement. Section III discusses the simulated and measured results, while the conclusions are in section IV.

\section{ANTENNA FORMULATION}

The surface-mounted omnidirectional antenna, illustrated in Figure 1 , consists of a slotted-metallic cavity enclosed, planar center-fed configuration designed using Roger RT/duroid $5880(\varepsilon r=2.2)$, with a thickness of $4.71 \mathrm{~mm}$.

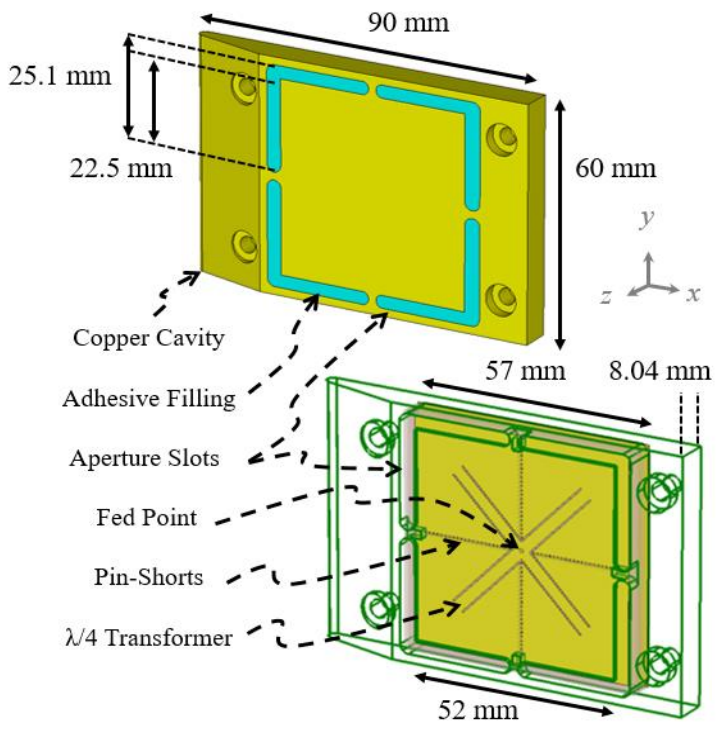

Fig. 1. Proposed tapered metal cavity embedded omnidirectional antenna formulation (with dimensions in $\mathrm{mm}$ ) 
The embedded configuration comprises of a radiating patch engraved with four $\lambda / 4$ transformers and ground shortening pins. The length of the square-shaped radiating patch mainly defines the operational frequency of the proposed antenna, in correlation with the shortening pins. This can be approximated by first analyzing the resonance of a periodic substrate integrated structure [19]. The width of pin short area of the antenna can be given by

$$
W_{\text {eff }}=W-\frac{d^{2}}{0.95 s},
$$

where $d$ is the diameter of the pin-short. The fundamental resonance frequency and $T E_{m, n}$ electric field of the substrate integrated waveguide surrounded by the pin-short was given in [20] as

$$
\begin{aligned}
f_{m, n} & =\frac{c}{2 \sqrt{\varepsilon_{r} \mu_{r}}} \sqrt{\left(\frac{m}{W_{e f f}}\right)^{2}+\left(\frac{n}{W_{e f f}}\right)^{2}}, \\
E_{z} & =A_{m, n} \sin \left(\frac{m \pi x}{W_{e f f}}\right) \sin \left(\frac{n \pi y}{W_{e f f}}\right) .
\end{aligned}
$$

While $m$ and $n$ are the mode numbers. Equation (1) to (3) can be used to engineer the four resonant areas within the resonator integrated with shortening pin walls. The transformers having an impedance of $200 \Omega$ each are designed using slots, to attain perfect impedance matching of $50 \Omega$ at the center of the radiator (fed-point) [21]. A center-fed symmetric structure contributes to achieve better radiation pattern symmetry in the azimuth plane, to avoid coverage fluctuation. Pin shortenings descending from the patch to the full ground bottom layer, establishing a loop like formation, leads to realizing an omnidirectional pattern by making all the four sides of the patch to radiate with maximum field intensity. Figure 2 exhibits that the electric field intensity is minimum at the points where the grounded pin shorts are used, whereas all sides of the patch contain well-distributed main propagation energy. A layer of Roger RT/duroid 5880 with a thickness of $1.575 \mathrm{~mm}$ is placed over the patch to provide insulation between the radiator and the DC grounded cavity. The DC grounding of an antenna is an efficient and effective method to avoid ESD (Electrostatic discharge) issues and to provide lightning protection for evading malfunctioning and damages [22].
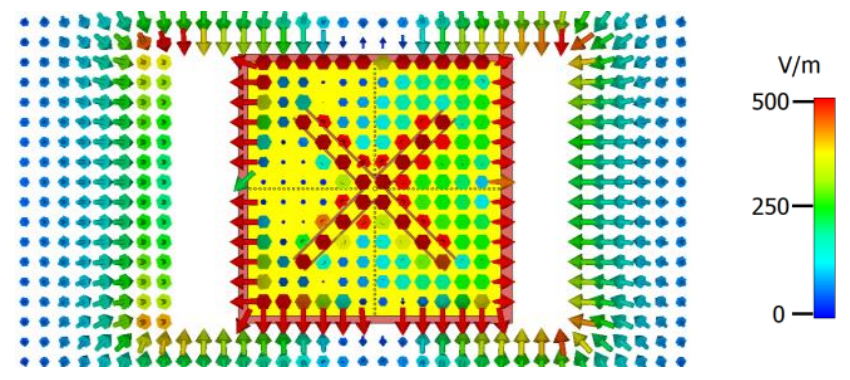

Fig. 2. Electric field behavior over the patch radiator

In the metal structure, aperture slots are formed on the edges of the embedded radiation patch to generate coupling and let energy to be radiated effectively in an omnidirectional manner. Narrowing the width of cavity aperture slots will reduce the horizontal gain and antenna efficiency, so the appropriate slot width is set to obtain good azimuth radiation performance. Figure 3 shows that the antenna efficiency varies with the change in width of the slots. The efficiency of the proposed antenna formulation increases with the increase in metallic slot width, till slot width reaches $2.6 \mathrm{~mm}$. With further increase in width of aperture slot, the antenna efficiency remains stable. To provide optimal strength to the antenna structure, the minimum slot width at which optimum efficiency can be achieved is used. The results show that, under the adjusted slot width, the antenna efficiency of the proposed antenna is greater than $85 \%$ over the whole operational frequency band.

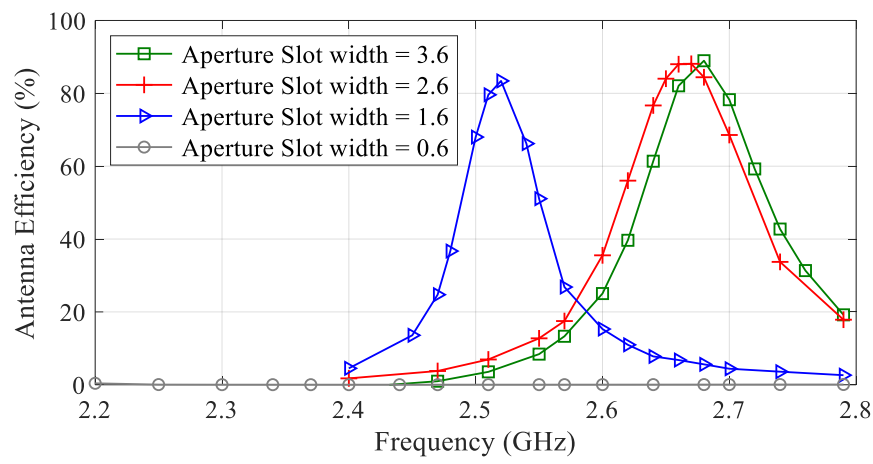

Fig. 3. Antenna efficiency of the designed formulation at different values of the metal cavity aperture slot width (dimension in $\mathrm{mm}$ )

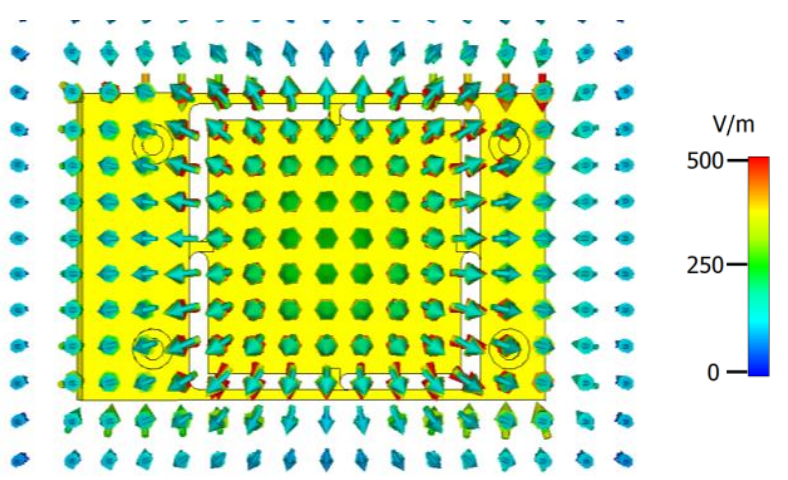

(a)

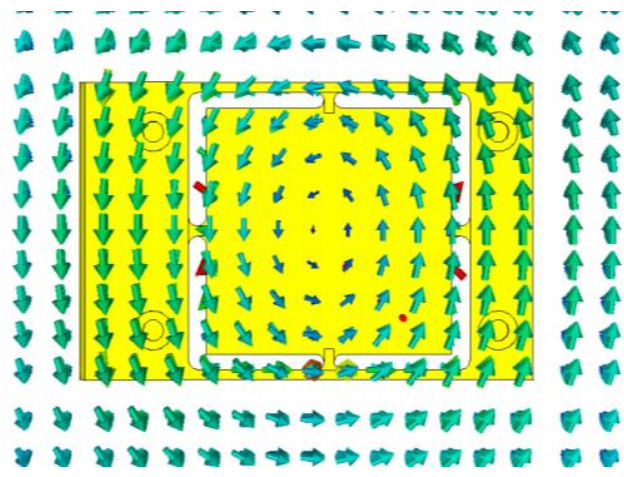

(b)

Fig. 4. Field behavior of the proposed antenna arrangement at $2.65 \mathrm{GHz}$, (a) Electric (b) Magnetic

The aperture slots of the metal structure are filled using ablative epoxy $\left(\varepsilon_{r}=3\right)$, to maintain physical strength and aerodynamic robustness of the designed antenna arrangement. Ablative epoxy is filled in a way, not only can cover the aperture slots, but can fill even the minor air gaps within the metal cavity, and avoid oxidation and 
ionization at extreme temperature conditions. Electric and magnetic fields distributions of the proposed antenna are viewable in Figure 4, demonstrating the operational mechanism and realization of omnidirectional radiation characteristics.

\section{Simulated AND Measured Results}

S-parameter simulations are performed using CST (Computer Software Technology), whereas measurements of the prototype are carried-out using Agilent Vector Network Analyzer. Simulated and measured reflection co-efficient contours along with the fabricated antenna picture are viewable in Figure 5. Simulated and measured results are well in harmony. Measured results show that the proposed antenna is effectively operational over the frequency band ranging from $2.63 \mathrm{GHz}$ to $2.67 \mathrm{GHz}$.

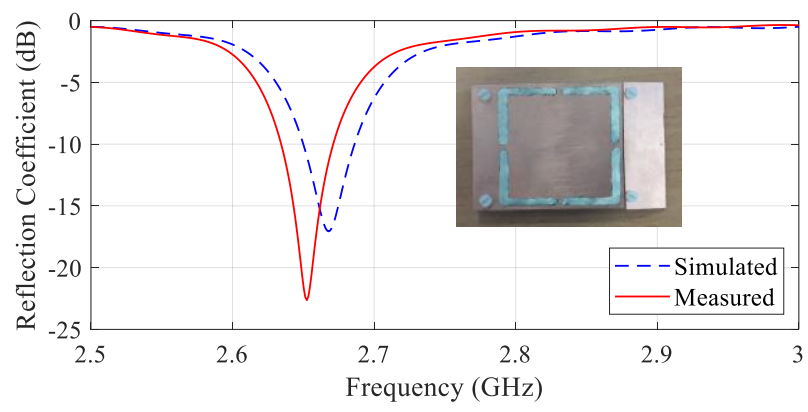

Fig. 5. Reflection co-efficient of the proposed Omni-directional antenna

Figure 6 displays the simulated and measured radiation patterns of the proposed antenna arrangement at $2.64 \mathrm{GHz}$. Simulated results are taken using CST software, whereas antenna measurements are conducted at NSI anechoic chamber. Radiation characteristics are analyzed along yz and xy planes, representing vertical and horizontal planes, respectively. Both the simulated and measured beam-patterns are in very good agreement and flaunts good omnidirectional radiation characteristics. Achieved omnidirectional radiation patterns are worthy of having placement liberty and large coverage area, along with having unwavering and steady communication during mobility and maneuvering of portable aerial platform.
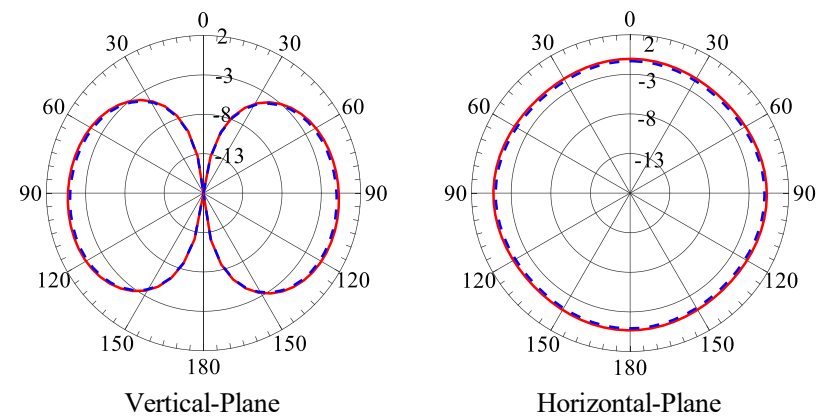

Fig. 6. Simulated (blue dashed) and Measured (red solid) radiation patterns of the demonstrated antenna in E-plane and H-plane at $2.64 \mathrm{GHz}$

Minimum horizontal gain and peak gain over the entire functional frequency band of the proposed ruggedized omnidirectional antenna are illustrated in Figure 7. Results depict that the proposed cavity embedded arrangement possesses good horizontal gain (more than $1.5 \mathrm{~dB}$ ) and low azimuth gain ripple of $\pm 0.7 \mathrm{~dB}$ through-out the operational bandwidth. Moreover, Figure 6 and Figure 7 shows that the radiation pattern characteristics remain stable and similar over the whole functional frequency band. Thus, the proposed antenna arrangement demonstrates very promising and commendable radiation characteristics, making antenna prospective candidate for airborne applications.

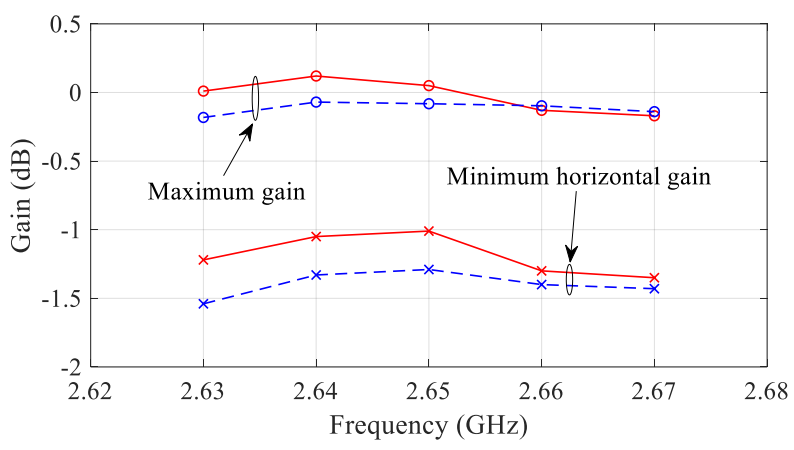

Fig. 7. Simulated (blue dashed) and Measured (red solid) minimum horizontal gain (cross) and peak gain (circle) of the proposed antenna

The proposed omnidirectional antenna formulation offers better radiation characteristics in comparison with several previously presented research efforts for airborne applications in-terms of horizontal gain and azimuth gain ripple, as can be seen from Table 1 . At the same time tapered cavity enclosed surface-mount antenna provide better robustness and aerodynamic stability being more ruggedized and metallic cavity protected / enclosed. Though, [12] presents a radome enclosed structure, but has air-gaps within a radome, which reduces the aerodynamic strength. Thus, the proposed formulation tends to be a superior option, especially for supersonic airborne platforms.

TABLE I. COMPARISON WITH PREVIOUS WORK

\begin{tabular}{|c|c|c|c|c|c|c|}
\hline Ref. & $\begin{array}{c}\text { Durability } \\
\text { / } \\
\text { Conformal } \\
\text { Technique }\end{array}$ & $\begin{array}{l}\text { Max. } \\
\text { Ant. } \\
\text { Dim. } \\
(\mathrm{mm})\end{array}$ & $\begin{array}{c}\text { Lowest } \\
\text { Functional } \\
\text { Freq. } \\
(\mathrm{MHz})\end{array}$ & $\begin{array}{l}\text { Min. } \\
\text { Az. } \\
\text { Gain } \\
\text { (dB) }\end{array}$ & $\begin{array}{l}\text { Horizontal } \\
\text { Gain } \\
\text { Ripple } \\
\text { (dB) }\end{array}$ & $\begin{array}{c}\text { Radome } \\
\text { or Metal } \\
\text { Protected }\end{array}$ \\
\hline [13] & $\begin{array}{l}\text { On-Glass } \\
\text { antenna }\end{array}$ & $1972 *$ & 30 & -14 & $>10$ & No \\
\hline [14] & $\begin{array}{c}\text { L-shaped } \\
\text { monopole } \\
\text { loaded } \\
\text { design }\end{array}$ & $130 *$ & 807 & -6 & 6 & No \\
\hline [15] & $\begin{array}{l}\text { Inverted L } \\
\text { with one } \\
\text { folding }\end{array}$ & $1510^{*}$ & 20 & -11.5 & 10 & Yes \\
\hline [16] & $\begin{array}{l}\text { Sabre-like } \\
\text { structure }\end{array}$ & $42 *$ & 2400 & -2 & 3.45 & No \\
\hline $\begin{array}{l}\text { This } \\
\text { work }\end{array}$ & $\begin{array}{c}\text { Tapered } \\
\text { Surface- } \\
\text { mount } \\
\text { cavity }\end{array}$ & $57 *$ & 2630 & -1.4 & 1.4 & Yes \\
\hline
\end{tabular}

\section{CONCLUSION}

A sturdy surface-mounted omnidirectional antenna is proposed, where the antenna consists of a cavity enclosed PCB configuration having $\lambda / 4$ transformers and ground shortening pins to generate omnidirectional beam-pattern. DC grounded, tapered, slotted cavity covers the PCB configuration to offer strength and protection against severe aerodynamic conditions. The proposed antenna arrangement possesses good linear yaw-plane gain, low horizontal gain ripple, symmetric azimuth pattern, decent antenna efficiency and stable omnidirectional radiation characteristics all over the operational frequency band. Furthermore, being non-protruding and having a 
simple feeding mechanism with the full ground plane, the proposed antenna does not have extravagant RCS and provide ease of mounting over the aerial vehicle.

\section{REFERENCES}

[1] L. Rufail, and J. Lurin, "Aircraft Cavity-Backed Non-Protruding Wideband Antenna," IEEE Ant. and Wireless Propagation. Letters, vol. 11, pp. 1108-1111, 2012, doi: 10.1109/LAWP.2012.2217727

[2] I. A. Baratta, and C. B. Andrade, "Installed Performance Assessment of Blade Antenna by Means of the Infinitesimal Dipole Model", IEEE Latin American Trans., vol. 14, (2), pp. 569-574, 2016, doi: 10.1109/TLA.2016.7437194

[3] K. Li, Y. Liu, Y. Jia, and Y. J. Guo, "A Circularly Polarized High Gain Antenna with Low RCS over a Wideband Using Chessboard Polarization Conversion Metasurfaces", IEEE Trans. on Ant. and Propagation, vol. 65, (8), pp. 4288 - 4292, 2017, doi: 10.1109/TAP.2017.2710231

[4] J. H. Bang, "Wideband low-profile null-filled monopole antenna for aircraft flush-mount applications", IET Electronics Letters, vol. 51, (21), pp. 1635 - 1637, 2015, doi: 10.1049/el.2015.1521

[5] C. K. Kim, L. M. Lee, H. C. Park, W. Hwang, and W. S. Park, "Impact damage and antenna performance of conformal load-bearing antenna structures", Smart Mater. and Structures, vol. 12, (5), pp. 672-679, 2003, doi: stacks.iop.org/SMS/12/672

[6] F. Abdi, Y. Xue, M. Garg, B. Farahmand, J. Housner, and K. Nikbin, "An analysis approach toward FAA certification for damage tolerance of aircraft components", The Aeronautical Journal, vol. 118, (1200), pp. 181 - 196, 2014, doi: https://doi.org/10.1017/S0001924000009064

[7] S. Abirami, E. F. Sundarsingh, and A. Harshavardhini, "A Compact Conformal Windshield Antenna for Location Tracking on Vehicular Platforms", IEEE Trans. on Vehicular Tech., vol. 68, (4), pp. 4047 4050, 2019, doi: 10.1109/TVT.2019.2898709

[8] C. R. Johnson, and H. Jasik, Antenna engineering handbook, $3^{\text {rd }}$ ed. New York, McGraw-Hill Book Company, 1992.

[9] J. J. Carr, and G. W. Hippisley, Practical Antenna Handbook, $5^{\text {th }}$ ed. McGraw-Hill/Tab Electronics, 2011.

[10] D. K. McNutt, "Shunt Antenna for Aircraft", U.S. Patent No. 7,511,674 B2, 31 Mar. 2009.

[11] Y. Liu, X. Li, L. Yang, and Y. Liu, "A Dual-polarized Dual-band Antenna with Omni-directional Radiation Patterns", IEEE Trans. on Ant. and Propagation, vol. 65, (8), pp. 4259 - 4262, 2017, doi: 10.1109/TAP.2017.2708093

[12] S. Y. Jun, A. Shastri, B. Sanz-Izquierdo, D. Bird, and A. McClelland, "Investigation of Antennas Integrated into Disposable Unmanned Aerial Vehicles", IEEE Trans. on Vehicular Tech., vol. 68, (1), pp. 604 - 612, 2019, doi: 10.1109/TVT.2018.2882791

[13] G. Byun, C. Seo, B. Jang, and H. Choo, "Design of Aircraft On-Glass Antennas Using a Coupled Feed Structure", IEEE Trans. on Ant. and Propagation, vol. 60, (4), pp. 2088 - 2093, 2012, doi: 10.1109/TAP.2012.2186234

[14] Z. Liu, Y. Zhang, Z. Qian, Z. P. Han, and W. Ni, "A Novel Broad Beam-width Conformal Antenna on Unmanned Aerial Vehicle", IEEE Ant. and Wireless Propagation. Letters, vol. 11, pp. 196 - 199, 2012, doi: 10.1109/LAWP.2012.2187321

[15] Y. J. Park, H. J. Ham, H. K. Ryu, K. S. Lee, and J. M. Woo, "Lowprofile Inverted-L aircraft antenna with one folding using ground edge current", IET Electronics Letters, vol. 50, (17), pp. 1188 - 1190, 2014 doi: 10.1049/el.2014.1920

[16] P. Liu, Y. Li, Z. Zhang, and Z. Feng, "Omnidirectional Dual-Polarized Antenna with Sabre-Like Structure", IEEE Trans. on Ant. and Propagation, vol. 65, (6), pp. 3221 - 3225, 2017, doi: 10.1109/TAP.2017.2690534

[17] Z. Tao, L. Jiong, L. Weimin, W. Huaji, and L. Humin, "Prescribed performance neural control to guarantee tracking quality for near space kinetic kill vehicle", Journal of Systems Engineering and Electronics, vol. 30, (3), pp. 573-586, 2019, doi: 10.21629/JSEE.2019.03.15

[18] F. Froes and R. Boyer, Additive Manufacturing for the Aerospace Industry: Elsevier, 2019, https://doi.org/10.1016/C2017-0-00712-7

[19] X. Li, C. C. Tzuang and H. Wu, "Dispersion characteristic a periodic substrate integrated waveguide of parallel metallic plates," 2014 International Conference on Numerical Electromagnetic Modeling and
Optimization for RF, Microwave, and Terahertz Applications (NEMO), Pavia, 2014, pp. 1-4.

[20] D. M. Pozar, Microwave Engineering, 4th ed. New York, NY, USA:Wiley, 2011.

[21] H. Nawaz, X. Liang, M. S. Sadiq, J. Geng, W. Zhu, and R. Jin, "Ruggedized Planar Monopole Antenna with a Null-Filled Shaped Beam", IEEE Ant. and Wireless Propagation. Letters, vol. 17, (5), pp. 933 - 936, 2018, doi: 10.1109/LAWP.2018.2825389

[22] K. Fujita, "MNL-FDTD/SPICE Method for Fast Analysis of Short-Gap ESD in Complex Systems", IEEE Trans. on Electromagnetic Compatibility, vol. 58, (3), pp. 709 - 720, 2016, doi: 10.1109/TEMC.2016.2532888. 